\title{
Rafael Huertas (coord.), Psiquiatría y antipsiquiatría en el segundo franquismo y la Transición, Madrid, Los libros de la Catarata, 2017.
}

\section{Rafael Huertas (coord.), Políticas de salud mental y cambio social en América Latina, Madrid, Los libros de la Catarata, 2017.}

Los libros Psiquiatría y antipsiquiatría en el segundo franquismo y la Transición y Políticas de salud mental y cambio social en América Latina coordinados por Rafael Huertas, reúnen once trabajos escritos por historiadores, médicos, psiquiatras, sociólogos y antropólogos que, a partir de estudios de casos concretos y metodologías sugerentes, dan cuenta de la dimensión social, cultural y política de la psiquiatría durante la segunda mitad del siglo XX en España y varios países de Latinoamérica. Ambos volúmenes forman parte de un proyecto colectivo y de cooperación académica que tienen por objetivos identificar los principales cambios políticoadministrativos ocurridos durante el tránsito de la higiene mental a la salud mental, entender cuáles fueron sus transformaciones teóricas y epistemológicas así como analizar los procesos de articulación de la psiquiatría a los movimientos sociales y contraculturales en una época de regímenes militares, violencia y persecución política, pero también de activismo sanitario, movilidad social y reivindicación de los derechos de los enfermos mentales. Publicados en la Colección Investigación y Debate, dentro de la serie "Psiquiatría y Cambio Social" de la casa editorial madrileña Los libros de la Catarata, estas obras examinan las ideas, prácticas, proyectos y experiencias terapéuticas que se llevaron a cabo en España, Argentina, Brasil, Chile, Colombia y México desde una perspectiva local e internacional, bajo un arco temporal 
amplio que inicia en la década de 1950 y concluye a finales de 1980. Una lectura atenta de los textos en su conjunto permite comprender los factores sociales que condujeron a la politización de la psiquiatría, específicamente, a la emergencia de liderazgos disidentes y voces contestatarias dentro de las agrupaciones psiquiátricas, así como las estrategias de resistencia social a las prácticas clínicas realizadas en los hospitales públicos y privados para enfermos mentales. Asimismo, se muestran con claridad el surgimiento de una variedad de planes, propuestas y acciones comunitarias encaminadas no sólo a la desinstitucionalización de los pacientes psiquiátricos (servicios ambulatorios, consultas externas, granjas campestres, entre otros), sino a la ponderación del trabajo grupal con los pacientes mediante comunidades terapéuticas que actuaban como islotes sanitarios de transformación y empoderamiento; experiencias que en todo caso buscaban dignificar la vidas de los "locos" más allá de los muros hospitalarios.

Los estudios que conforman los dos volúmenes procuran alejarse de la historia intelectual, por el contrario, tienen el mérito de intercalar con astucia la historia de las ideas con la historia social y cultural; de hecho, en varios trabajos los autores exploran novedosas rutas de análisis para el conocimiento de la historia política de la psiquiatría. En conjunto, cada capítulo muestra que los objetos de la psiquiatría en perspectiva histórica no se reducen a las teorías, instituciones, psiquiatras y pacientes, sino que posibilitan la comprensión de las tensiones, disputas y negociaciones entre distintos actores: regímenes dictatoriales, organismos internacionales, profesionales disidentes, intelectuales contestatarios, reporteros de investigación, activistas redentores y una sociedad civil cada vez más crítica del establishment psiquiátrico. La diversidad de fuentes utilizadas por los autores permite dimensionar los aspectos políticos de la disciplina: memorias de congresos, folletos, revistas culturales, diarios 
de campo, novelas, informes administrativos, prensa sensacionalista, legislaciones, testimonios inéditos y entrevistas realizadas a los protagonistas de aquella época. Sorprende en la mayoría de los trabajos la omnipresencia que adquirió el Estado en el Madrid del segundo franquismo, en Brasil después de la dictadura, en Colombia posterior a la época de La Violencia, en la Argentina durante los años de plomo, en el México de la guerra sucia e incluso en Chile antes del golpe militar en 1973. Una mirada global de los textos permite reflexionar sobre los diferentes procesos de intervención estatal en materia de salud mental: ya sea como instancia de financiamiento económico; plataforma de desarrollo científico e institucional; ente regulador de las disputas político-sanitarias y figura persecutoria de las actividades pretendidamente subversivas de grupos inconformes que optaron por alternativas terapéuticas para la atención de los locos.

En lo particular, los seis capítulos que conforman Psiquiatría y antipsiquiatría en el segundo franquismo y la Transición, muestran con profundidad analítica las metáforas sociales de la locura en una época de crítica antifranquista, de esta manera, la defensa por la salud mental también se volvió símbolo de luchas políticas. Por ejemplo, entre 1955 y 1975 funcionó el Patronato Nacional de Asistencia Psiquiátrica (PANAP), proyecto de sectorización de servicios sanitarios que buscó organizar y modernizar la asistencia psiquiátrica; sin embargo, como lo muestra David Simón Lorda, éste fracasó por la falta de recursos económicos y el respaldo de otros profesionales de la salud mental. Debido al repunte de la economía y al clima de hostilidad política durante la dictadura franquista, el régimen estaba convencido como señala Ricardo Campos- que muchas de las transformaciones podían ser los detonantes para la manifestación de comportamientos transgresores y subversivos, razón por la cual en 1970 se promulgó la Ley de Peligrosidad y Rehabilitación Social. Con esta medida se 
estigmatizó a los enfermos mentales y procuró castigar jurídicamente a todos aquellos que se apartaban de la moral que representaban los miembros del Estado. Pese a que la ley aseguraba la defensa social (vigente hasta 1995), eso no impidió que surgieran acciones de protesta en los manicomios españoles. Para Rafael Huertas, la Coordinadora Psiquiátrica Nacional (1971) no sólo aglutinó las experiencias de lucha de residentes en otros Hospitales Psiquiátricos en demanda de mejores condiciones salariales y de mayor cobertura social, sino que fue un espacio de activismo psiquiátrico que procuró la transformación de la asistencia en España. Las luchas por el cambio de las instituciones, sostiene Patricia Mayayo, lograron despertar el ánimo reformista de personajes como Enrique González Duro que, junto con otro grupo de profesionales, utilizaron el arte como un medio de empoderamiento de los pacientes en el Hospital de Día de Madrid, en el que se llevaron a cabo prácticas de psiquiatría alternativa que a su vez tuvieron un fuerte impacto en las revistas culturales como Viejo Topo, Triunfo, Interviú, analizadas por Oscar Martínez Azumendi. Si bien sectores amplios de la sociedad actuaban en favor de la transformación asistencial, los intelectuales de la revista Ajoblanco lograron abrir espacios para el debate público y la recepción de un conjunto de teorizaciones contestatarias de la cultura psi, en este sentido, señala Fabiola Irisarri, los impresos se volvieron voceros de colectivos movilizados en el ámbito de la salud mental. El cuestionamiento al modelo hegemónico asistencial y el papel preponderante de las revistas culturales, fueron cruciales tanto en la definición de modelos alternativos como en la configuración de imaginarios de denuncia y reivindicación de prácticas subversivas a la psiquiatría estatal.

Por su parte, Políticas de salud mental y cambio social en América Latina, reúne cinco trabajos que muestran algunas similitudes y diferencias respecto al caso español. El impulso, desarrollo y estancamiento de iniciativas dirigidas al campo de la salud mental en Argentina, 
Brasil, Chile, Colombia y México estuvieron vinculadas a políticas sanitarias internacionales cuya operatividad institucional estuvo sujeta a contextos sociales inciertos: violencias sistemáticas, persecución política y guerra sucia. Juan Carlos Stagnaro y Norberto Aldo Conti examinan, a partir de sus testimonios y una documentación exhaustiva, cómo la dictadura militar (1976-1983) minó los esfuerzos de los profesionales de la salud mental. Aunque surgieron colonias psiquiátricas y hospitales de día, los representantes fueron perseguidos y sus espacios clausurados por considerarse focos subversivos de inspiración comunista. Los profesionales de la salud mental realizaron fuertes cuestionamientos al modelo vertical imperante en las instituciones hospitalarias, por ejemplo, las propuestas del médico-cirujano Juan Marconi Tassara fueron cruciales en el periodo anterior al golpe de Estado en Chile. De acuerdo a Claudia Araya y César Leyton, Marconi implementó un modelo intracomunitario de salud mental desde una perspectiva marxista, en el que participó la Universidad de Chile con diversas unidades sanitarias en el sur de Santiago. Marconi enarboló una "revolución cultural” que pretendía transformar el sistema sanitario a través de la alfabetización y sensibilización de la sociedad. Otras experiencias alternativas surgieron en Brasil con el objetivo de contrarrestar la centralización de los sistemas de salud. Con la llegada de Franco Basaglia en los años sesenta surgieron intensos debates entre los profesionales de la salud, se crearon colonias y hospitales ambulatorios, así como comunidades terapéuticas públicas y privadas, muchas de ellas ligadas a instituciones académicas; sin embargo, como apuntan André Luiz de Carvalho y Anat teresa Venancio, solo el modelo ambulatorio logró erigirse en política pública. Por su parte, Álvaro Casas y Jana Congote destacan que desde 1970 se implementó en Colombia el Sistema Nacional de Salud, instancia a partir de la cual surgieron consultas externas realizadas en novísimos hospitales psiquiátricos en Antioquia, Cali y Medellin, instituciones destinadas a la atención psiquiátrica de una sociedad pobre y afectada 
por los años de época de La Violencia. Finalmente, Oliver Hernández, Cristina Sacristán y Teresa Ordorika muestran para el caso mexicano que los psiquiatras-funcionarios del Estado en el periodo de la guerra sucia, apostaron por defender el modelo hospitalario que impulsar la atención primaria estipulada desde la OMS, debido a que el gobierno destinaba recursos para su funcionamiento y porque empataba muy bien con la perspectiva biológica con el uso de psicofármacos. En los estudios incluidos en esta obra, llama la atención que la "reforma psiquiátrica” no siempre significó los mismo en cada contexto ni tuvo las repercusiones que los impulsores del cambio esperaban, razón por la cual, el anhelado cambio estructural y los proyectos emprendidos en el ámbito de la salud mental en América Latina, resultaron insuficientes para subsanar el enorme reto que suponía la prevalencia de las enfermedades mentales en los hospitales psiquiátricos. En definitiva, las investigaciones reunidas en ambos libros permiten comprender que las últimas décadas del siglo XX fueron de experimentación, espíritu contestatario y diversificación de experiencias terapéuticas disidentes, un periodo contrastante marcado por las ansias de transformación de muchos médicos, psiquiatras, psicoanalistas y profesionales de la salud mental comprometidos con el cambio social, y por la vorágine de la violencia estatal en sus distintas formas, circunstancia que en varios países frenó, condicionó, impidió, auspició y/o toleró prácticas alternativas a la psiquiatría oficial. Sin duda, la lectura de los libros imprime una visión amplia, compleja e internacional de la historia política de la psiquiatría durante el periodo reformista. Una psiquiatría cuestionada y que en el imaginario literario contemporáneo sigue representando el espíritu crítico de aquellos años. En la novela del escritor lusitano Antonio Lobo Antunes Conocimiento del infierno, uno de los tantos locos confinados en 1973 en el Hospital Miguel Bombarda, señaló con pesadumbre que para él la psiquiatría solo era "un infierno, pensó, [así como] son los Tratados de Psiquiatría, el infierno es la invención de la locura de los médicos” (p.56). Una voz elocuente 
que en varios aspectos sintetiza el clamor de una época crítica, de transición y cambio en los terrenos de la salud mental internacional.

José Antonio Maya González Universidad Autónoma Metropolitana Unidad Xochimilco jomayago@gmail.com 